\title{
The Reliability and Accuracy of the Garmin Vector 3 Power Pedals
}

\section{Submission Type}

Journal of Sports Engineering and Technology - Technical Note

\section{Authors and Affiliations}

Tom Dickinson ${ }^{1}$ and James Wright ${ }^{1^{*}}$

${ }^{1}$ School of Sport, Health and Social Science, Solent University, Southampton, UK

Dr James Wright (Corresponding Author ${ }^{*}$ )

Solent University

School of Sport, Health and Social Science

East Park Terrace, Southampton

Hampshire, SO14 OYN, UK

E: james.wright@solent.ac.uk

T: 02380313955

Abstract Word Count: 210 words

Word Count: 1424 words (excluding headings and tables)

Number of Figures: 2

Number of Tables: 2 


\section{Abstract}

The aims of this study were to 1) investigate the reliability of the Garmin Vector 3 (V3) pedals, and 2) compare power output and cadence between the Lode Excalibur Sport ergometer and the V3 pedals. Seven male cyclists completed six x 2-min sub-maximal cycling stages $(100,150,200,250$, 300 and $350 \mathrm{~W}$ ) and two x 10-s maximal sprints, completed on two occasions within seven days. A Mann-Whitney U test identified significant differences between the Lode Excalibur Sport and the V3 pedals at $150-350 \mathrm{~W}$ and during all-out sprinting $(P<0.05)$ with a mean relative difference during sub-maximal cycling of $1.8 \%$. Results also suggested there was no significant differences between the Lode Excalibur Sport and V3 pedals for cadence at all power outputs tested $(P>0.05)$, with a mean relative difference of $0.2 \%$. Results suggest that the $\mathrm{V} 3$ pedals are reliable for both power output and cadence with a coefficient of variation of $<5.05 \%$ and $<3.87 \%$, respectively. Furthermore, the technical error of measurement for power output was $2.4-5.3 \mathrm{~W}$ between $100-350 \mathrm{~W}$, and $<8.04$ rev. $\mathrm{min}^{-1}$ for cadence at all power outputs tested. It is suggested that the V3 pedals are reliable and accurate during sub-maximal testing; however, the V3 pedals over-estimate power output during all-out sprinting.

Keywords validation, power meter, laboratory-based test, field-based testing 


\section{Introduction}

Power meters are regularly used within cycling to allow coaches to set individualised training plans based on the power output and cadence data collected from training and race performances. ${ }^{1}$ Laboratory-based ergometers are ideal for research; however, with a purchase price of more than $\$ 20,000$, recent research has focused on validating cheaper more portable systems. ${ }^{2}$ The development of the cycle-mounted power meter has provided the opportunity to monitor performance (e.g. power output and cadence) using the athlete's bicycle, rather than being restricted to a laboratory-based ergometer. ${ }^{3,4,5}$ The SRM Powermeter (crank) is regarded as the "gold standard" cycle-mounted power meter. ${ }^{1}$

Pedal-based power meters have recently been developed at a lower cost compared to traditional systems. Several studies have focused on their reliability and validity of these meters. It has previously been suggested that the Garmin Vector pedals (V1) overestimate power output ${ }^{6,7}$, with a typical error of $3.3 \%(20 \mathrm{~W})^{6}$. In contrast, studies suggested that the second version of the Garmin Vector pedals (V2) are comparable to the SRM Powermeter, with no significant difference in power output during sub-maximal cycling observed; however, significant differences were seen during sprint cycling. ${ }^{8}$ The P1 pedals have also been reported to demonstrate excellent levels of agreement when compared to a Wattbike Pro cycle ergometer during a $16.1 \mathrm{~km}$ time-trial, with an intra-class correlation of $>0.8 .^{9}$ Both the V2 and P1 pedals have demonstrated acceptable test-retest reliability during sub-maximal cycling. Previous studies have suggested that the P1 pedals are reliable between $150-500 \mathrm{~W}$, with a coefficient of variation (CV) of $2.3 \%^{10}$, and between $\sim 100-400 \mathrm{~W}$, with a CV of $\leq 2 \% .{ }^{11}$ Similarly, the V2 pedals have been reported as reliable between $100-300 \mathrm{~W}$ when compared to the SRM Powermeter (CV $=\sim 3.0 \%) .{ }^{8}$ Garmin has recently released the third version of the Vector power pedals (V3), but to date, it has not been established if these are reliable or accurate.

Therefore, the aim of this study was to 1 ) investigate the test-retest reliability of the V3 pedals, and 
2) compare power output and cadence between the V3 pedals and the Lode Excalibur Sport ergometer.

\section{Methods}

\section{Participants}

Seven male cyclists (mean \pm SD: age $21 \pm 1$ years, $181.6 \pm 8.0 \mathrm{~cm}$, body mass $75.3 \pm 9.9 \mathrm{~kg}, \dot{\mathrm{V}}_{2 \max }$ $58.3 \pm 7.0 \mathrm{ml} \cdot \mathrm{kg}^{-1} \cdot \mathrm{min}^{-1}$ ) were recruited to take part in this study, with all providing written informed consent. The study was approved by the host university's ethics committee.

\section{Procedures}

Testing was completed using an electronically-braked cycle ergometer (Excalibur Sport, Lode, The Netherlands), ${ }^{12}$ with the power pedals (V3, Garmin, USA) installed and zeroed following the manufacturer's guidelines. For each testing session, the participants wore their own cycling shoes, fitted with Vector cleats (Arc 2, Garmin, USA). Following a 10-min warm-up, participants cycled at a self-selected cadence at $350 \mathrm{~W}, 300 \mathrm{~W}, 250 \mathrm{~W}, 200 \mathrm{~W}, 150 \mathrm{~W}$ and $100 \mathrm{~W}$ for $2 \mathrm{~min}$, each separated by a 4-min rest period. Once these tests were completed, the participants were allowed a $10 \mathrm{~min}$ rest period, followed by $2 \times 10$-s maximal sprints from a rolling start $\left(90 \mathrm{rev} \cdot \mathrm{min}^{-1}\right)$ whilst in a seated position. A 2-min rest was allowed in between maximal sprint tests. This testing procedure was completed on two occasions, separated by 48 hours.

\section{Data Analysis}

Power output and cadence for the V3 pedals were recorded using a bike computer (Edge 820, Garmin, USA) and downloaded for analysis. The sampling frequencies of the V3 pedals and the Lode Excalibur Sport were $1 \mathrm{~Hz}$ and $4 \mathrm{~Hz}$, respectively. A Mann-Whitney $\mathrm{U}$ test and limits of agreement (LOA) were used to make comparisons between the V3 pedals and the Lode Excalibur Sport, with CV 
and absolute technical error of measurement (TEM) used to determine the test-retest reliability of the V3 pedals. TEM was calculated using Eq. 1 (1):

$\mathrm{TEM}=\sqrt{\frac{\sum D^{2}}{2 n}}$

, where $\sum D^{2}$ represents the sum of deviations raised to the $2^{\text {nd }}$ power. ${ }^{13}$ All data are reported as mean \pm SD with statistical significance set to $P<0.05$.

\section{Results}

A Mann-Whitney $U$ test identified significant differences between the Lode Excalibur Sport and the V3 pedals for power output at $150 \mathrm{~W}(P<0.001), 200 \mathrm{~W}(P=0.001), 250 \mathrm{~W}(P<0.001), 300 \mathrm{~W}(P<$ $0.001), 350 \mathrm{~W}(P<0.001)$ and during all-out sprinting $(P=0.001)$. There were no significant differences between the Lode Excalibur Sport and the V3 pedals at $100 \mathrm{~W}(P=0.210)$. Additionally, a Mann-Whitney U test identified no significant differences for cadence at $100 \mathrm{~W}(P=0.946), 150 \mathrm{~W}(P$ $<0.982), 200 \mathrm{~W}(P=0.982), 250 \mathrm{~W}(P<0.946), 300 \mathrm{~W}(P<0.982), 350 \mathrm{~W}(P<0.910)$ and during allout sprinting $(P=0.635)$ The mean difference between the Lode Excalibur Sport and V3 pedals was $1.8 \%$ for power output during sub-maximal cycling; however, this increased to $21 \%$ during all-out sprinting (Figs. 1 and 2). The mean difference for cadence was $0.2 \%$ for all tested power outputs (Table 1).

During sub-maximal cycling, the V3 pedals had a mean CV of $1.4 \%$ and a TEM of $3.0 \mathrm{~W}$ for power output. For cadence, the mean CV was $2.4 \%$ and the mean TEM was $3.6 \mathrm{rev} \cdot \mathrm{min}^{-1}$. During all-out sprinting, the CV and TEM for both power output and cadence were higher than sub-maximal cycling (CV $=5.1 \%$ and $3.9 \%$, respectively; TEM $=74.8 \mathrm{~W}$ and $8.0 \mathrm{rev} \cdot \mathrm{min}^{-1}$, respectively) (Table 2 ). 
***Insert Figures 1 and 2 near here ${ }^{* * *}$ 
Table 1. Comparisons in power output and cadence between the Lode Excalibur Sport and the Garmin Vector 3 pedals.

\begin{tabular}{|c|c|c|c|c|c|c|c|c|}
\hline & \multicolumn{3}{|c|}{ Power Output } & \multicolumn{5}{|c|}{ Cadence } \\
\hline $\begin{array}{l}\text { Lode Excalibur } \\
\text { Sport } \\
\text { (W) }\end{array}$ & $\begin{array}{l}\text { Garmin } \\
\text { Vector } 3 \\
\text { (W) }\end{array}$ & $\begin{array}{l}\text { Absolute } \\
\text { Difference } \\
\text { (W) }\end{array}$ & $\begin{array}{l}\text { Relative } \\
\text { Difference } \\
(\%)\end{array}$ & $\begin{array}{c}\text { Lode Excalibur } \\
\text { Sport } \\
\left(\mathrm{rev} \cdot \mathrm{min}^{-1}\right)\end{array}$ & $\begin{array}{c}\text { Garmin } \\
\text { Vector } 3 \\
\left(\text { rev } \cdot \min ^{-1}\right)\end{array}$ & $\begin{array}{l}\text { Absolute } \\
\text { Difference } \\
\left(\text { rev } \cdot \mathrm{min}^{-1}\right)\end{array}$ & $\begin{array}{l}\text { Relative } \\
\text { Difference } \\
\text { (\%) }\end{array}$ & $\begin{array}{l}3 \\
4\end{array}$ \\
\hline $100 \pm 0$ & $100 \pm 3$ & $0 \pm 3$ & 0.0 & $89 \pm 15$ & $89 \pm 15$ & $0 \pm 0$ & 0.0 & 5 \\
\hline $150 \pm 0$ & $153 \pm 3$ & $3 \pm 3$ & 1.9 & $90 \pm 15$ & $90 \pm 15$ & $0 \pm 0$ & 0.0 & 6 \\
\hline $200 \pm 0$ & $205 \pm 4$ & $5 \pm 4$ & 2.5 & $90 \pm 15$ & $90 \pm 15$ & $0 \pm 0$ & 0.0 & 7 \\
\hline $250 \pm 0$ & $256 \pm 4$ & $6 \pm 4$ & 2.4 & $89 \pm 15$ & $89 \pm 15$ & $0 \pm 0$ & 0.0 & 8 \\
\hline $300 \pm 0$ & $305 \pm 5$ & $5 \pm 5$ & 1.7 & $90 \pm 16$ & $90 \pm 16$ & $0 \pm 0$ & 0.0 & 9 \\
\hline $350 \pm 0$ & $357 \pm 4$ & $7 \pm 4$ & 2.0 & $92 \pm 16$ & $93 \pm 16$ & $1 \pm 0$ & 1.1 & 10 \\
\hline $900 \pm 128$ & $1111 \pm 152$ & $211 \pm 24$ & 21.0 & $165 \pm 10$ & $166 \pm 11$ & $1 \pm 1$ & 0.6 & 11 \\
\hline
\end{tabular}


Table 2. Coefficient of Variation (CV) and Absolute Technical Error of Measurement (TEM) between Testing Sessions 1 and 2 for power output and cadence (including 95\% Confidence Intervals).

\begin{tabular}{lcccc}
\hline \multirow{2}{*}{ Power Output } & \multicolumn{2}{c}{ Power Output } & \multicolumn{2}{c}{ Cadence } \\
\cline { 2 - 5 } & CV (\%) & TEM (W) & CV (\%) & TEM (rev· min $\left.^{-1}\right)$ \\
\hline $100 \mathrm{~W}$ & $2.5(1.4-3.7)$ & $2.9(1.8-4.0)$ & $2.7(-0.9-6.3)$ & $4.4(1.4-7.4)$ \\
$200 \mathrm{~W}$ & $1.4(0.9-1.9)$ & $2.4(1.6-3.2)$ & $1.7(-1.1-4.5)$ & $3.3(0.9-5.6)$ \\
$250 \mathrm{~W}$ & $1.2(0.6-1.8)$ & $2.9(1.6-4.2)$ & $1.5(-0.1-3.1)$ & $2.0(0.7-3.3)$ \\
$300 \mathrm{~W}$ & $0.9(0.2-1.6)$ & $3.3(1.4-5.2)$ & $2.2(-0.6-5.0)$ & $3.3(1.1-5.5)$ \\
$350 \mathrm{~W}$ & $1.4(0.6-2.2)$ & $5.3(2.9-7.7)$ & $3.1(-0.6-6.8)$ & $4.5(1.6-7.4)$ \\
Peak Power & $0.7(0.3-1.1)$ & $3.0(1.7-4.4)$ & $3.1(0.6-5.5)$ & $4.1(1.7-6.5)$ \\
Mean (100-350 W) & $5.1(0.9-9.2)$ & $74.8(33.3-116.3)$ & $3.9(1.6-6.1)$ & $8.0(4.2-11.9)$ \\
\hline
\end{tabular}


27 The findings of this study suggest that the V3 pedals provide a reliable and accurate measure of power output and cadence during sub-maximal cycling between 100 and $350 \mathrm{~W}$. The heteroscedastic nature of power output can be observed from Figs. 1 and 2 with an increased error and mean bias during higher powers. The mean relative difference between the Lode Excalibur Sport and the V3 pedals was $1.8 \%$ for power output, and $0.2 \%$ for cadence during sub-maximal cycling. The results suggest that the V3 pedals are reliable for power output and cadence, with a CV of $<5.1 \%$ and $<3.9$, respectively, observed at all tested power outputs. Additionally, the TEM for power output was 2.4-5.3 $\mathrm{W}$ when tested between $100-350 \mathrm{~W}$, with a TEM for cadence of $<8.0 \mathrm{rev} \cdot \mathrm{min}^{-1}$ observed during all power outputs.

The results of this study are comparable to studies published using earlier versions of the Garmin Vector pedals with a CV of $2.0 \%$ for the V1 pedals reported between 150 and $350 \mathrm{~W}^{7}$ Additionally, these results are similar to the reported CV of $\sim 3.0 \%$ of the V2 pedals when tested between $100-300$ W. ${ }^{8}$ The results of the present study are also comparable to other pedal-based systems with a CV of $<6.3 \%$ observed for the PowerTap P1 pedals when tested at sub-maximal power outputs and during all-out sprinting. ${ }^{11}$ Additionally, the TEM of $75.8 \mathrm{~W}$ observed during all-out sprinting is similar to the PowerTap P1 pedals $(75.1 \mathrm{~W})^{11}$. It is noted, however, that the CV observed during sub-maximal cycling $(100-350 \mathrm{~W})$ in the present study is slightly higher than those reported by Czajkowski et al. ${ }^{14}$, who reported a CV of $0.7 \%$ for power output between 150 and $350 \mathrm{~W}$.

A significant difference in power output was observed between the V3 pedals and the Lode Excalibur Sport at all power outputs measured above $100 \mathrm{~W}$. Similar conclusions have also been made for the 
estimate power output during sub-maximal cycling. The results of the present study also supports previous literature that suggests that the greatest error in measurement occurs at higher power outputs (e.g. sprinting). These results could be explained by the different sampling frequencies of the Lode Excalibur Sport $(4 \mathrm{~Hz})$ and V1 pedals $(1 \mathrm{~Hz})$, and it has been suggested that power output should be sampled at a minimum of $5 \mathrm{~Hz}$ when testing peak power output. ${ }^{15}$ Therefore, it may be expected that the V3 pedals would measure differently to the Lode Excalibur Sport during all-out sprinting.

This study provides valuable information to cyclists, coaches or researchers who plan to use the V3 pedals for training or research. It is suggested that additional research is carried out on pedal-based power meters across a full range of the power curve; however, it is acknowledged that this is difficult without the use of a calibration rig.

62

\section{Conclusion}

The results of this study suggest that the V3 pedals provide reliable and accurate data between 100 and $350 \mathrm{~W}$ when compared to a Lode Excalibur Sport ergometer. It is suggested that these pedals can be used by cyclists at power outputs $<350 \mathrm{~W}$ with confidence. Due to the increased CV and TEM at higher power outputs, some care should be exercised if using these pedals to monitor sprint performance.

\section{Acknowledgements}

The authors would like to thank all the participants who volunteered to take part in this study. The authors would also like to thank Dr Lee Bridgeman and Chris Morphew for their assistance during data collection. 


\section{Declaration of conflicting interests}

76 The author(s) declared no potential conflicts of interest with respect to the research, authorship,

77 and/or publication of this article. 


\section{References}

1. Passfield, L, Hopker, JG, Jobson, SA, et al. Knowledge is Power: Issues of Measuring Training and Performance in Cycling. Journal of Sports Sciences 2017; 35(14): 1426-1434.

2. Peiffer, J and Losco, B. Reliability/Validity of the Fortius Trainer. Int J Sports Med 2011; 32(5): 353-356.

3. Jones, SLP and Passfield, L. The dynamic calibration of bicycle power measuring cranks. Engineering of Sport 1998; 265-274.

4. Earnest, $\mathrm{CP}$, Wharton, RP, Church, TS, et al. Reliability of the Lode Excalibur Sport Ergometer and Applicability to Computrainer Electromagnetically Braked Cycling Training Device. J Strength Cond Res 2005; 19(2): 344-348.

5. Bini, RR, Hume, PA and Cerviri, A. A comparison of cycling SRM crank and strain gauge instrumented pedal measures of peak torque, crank angle at peak torque and power output. Procedia Engineering 2011; 13: 56-61.

6. Novak, AR and Dascombe, BJ. Agreement of power measures between Garmin Vector and SRM cycle power meters. Meas Phys Educ Exerc Sci 2016; 20(3): 167-172.

7. Bouillod, A., Pinot, J, Soto-Romero, G, et al. Validity, sensitivity and reproducibility of Stages and Garmin Vector power meters when compared with SRM device. Int J Sport Physiol Perform 2017; 12(8): 1023-1030.

8. Nimmerichter, A, Schnitzer, L, Prinz, B, et al. Validity and reliability of the Garmin Vector power meter in laboratory and field cycling. Int J Sports Med 2017; 38(6): 439-446.

9. Whittle, C, Smith, N, and Jobson, S. Validity of PowerTap P1 Pedals during Laboratory-Based Cycling Time Trial Performance. Sports 2019; 6(3), 92.

10. Pallares, JG and Lillo-Bevia, JR. Validity and Reliability of the PowerTap P1 Pedals Power Meter. Journal of Sports Science and Medicine 2018; 17(2), 305-311 
11. Wright, J, Walker, T, Burnet, S, et al. The Reliability and Validity of the PowerTap P1 Power Pedals Before and After 100 Hours of Use. Int J Sports Physiol Perform 2019; 14(6): 855-858.

12. Reiser, M, Meyer, $\mathrm{T}$, Kindermann, et al. Transferability of workload measurements between three different types of ergometer. European Journal of Applied Physiology 2000; 82(3): 245249.

13. Perini, TA, de Oliveira, GL, Ornellas, JD, et al. Technical error of measurement in anthropometry. Revista Brasileira de Medicina do Esporte 2005; 11(1), 86-90.

14. Czajkowski, M, Bouillod, A, Dauriannes, A, et al. Validity and reproducibility of the Powertap P1 power meter when compared with SRM device. J Sci Cycling 2016; 5(2): 9-10.

15. Santos, EL, Novaes, JS, Reis VM, et al. Low Sampling Rates Bias Outcomes from the Wingate Test. Int J Sports Med 2010; 31: 784-789. 


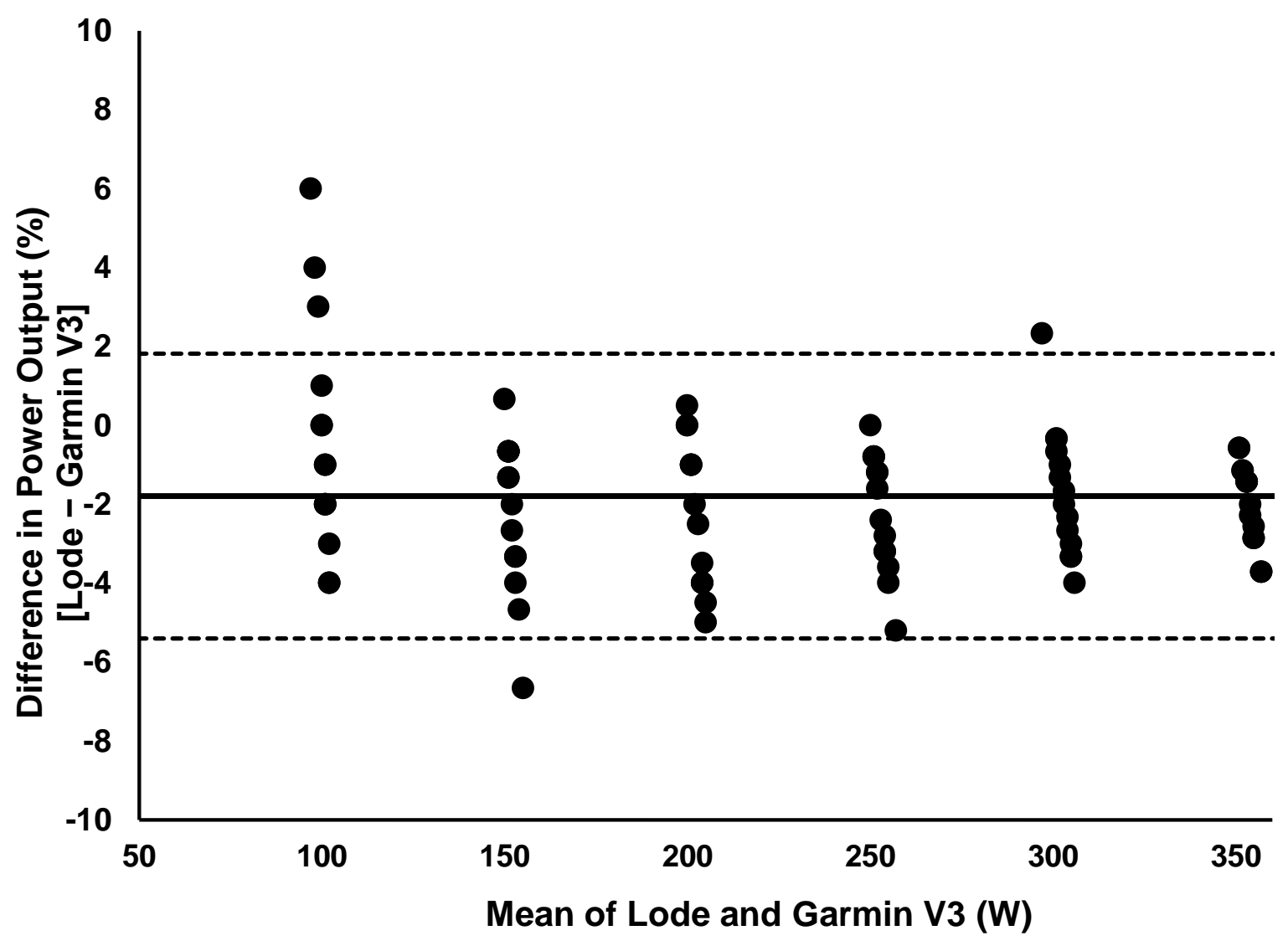

126 Figure 1. Bland-Altman Plot showing the limits of agreement between Lode Excalibur Sport and 127 Garmin V3 power pedals at $100 \mathrm{~W}, 150 \mathrm{~W}, 200 \mathrm{~W}, 250 \mathrm{~W}, 300 \mathrm{~W}$ and $350 \mathrm{~W}$. The solid line 128 represents the mean difference in power output, with the dashed lines representing the $95 \%$ limits 129 of agreement. 


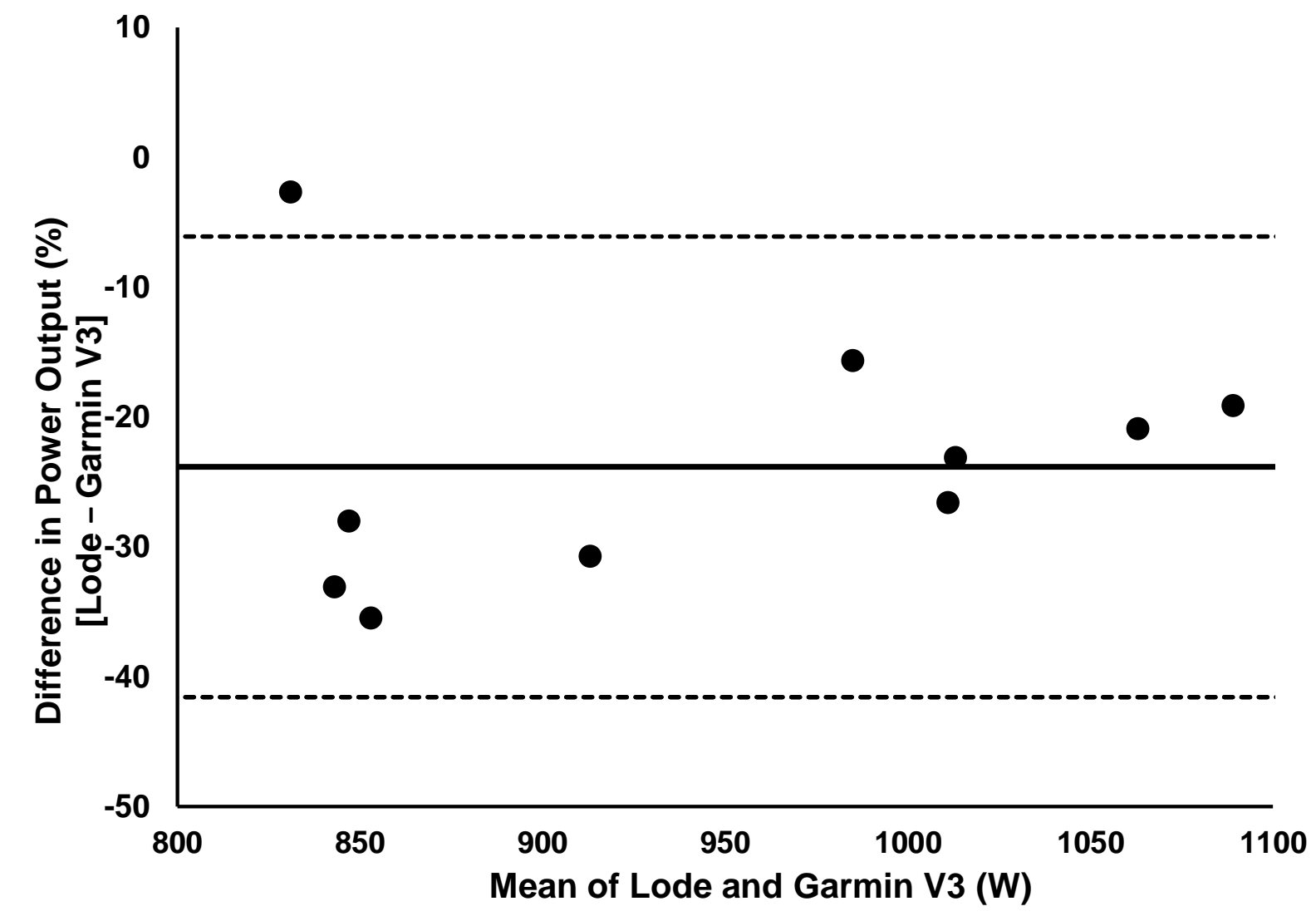

133 Figure 2. Bland-Altman Plot of the differences between the Lode Excalibur Sport and Garmin V3 134 power pedals during all-out sprinting. The solid horizontal line represents the mean bias, with the 135 dashed lines represented $95 \%$ confidence intervals. 